\title{
Using E-Learning and ICT Courses in Educational Environment: A Review
}

\author{
Hadi Salehi ${ }^{1}$, Mohammad Shojaee ${ }^{1} \&$ Susan Sattar ${ }^{1}$ \\ ${ }^{1}$ Faculty of Humanities, Najafabad Branch, Islamic Azad University, Najafabad, Isfahan, Iran \\ Correspondence: Hadi Salehi, Faculty of Humanities, Najafabad Branch, Islamic Azad University, Najafabad, \\ Isfahan, Iran. E-mail: hadisalehi1358@yahoo.com
}

Received: September 23, 2014 Accepted: October 31, 2014 Online Published: December 17, 2014

doi:10.5539/elt.v8n1p63 URL: http://dx.doi.org/10.5539/elt.v8n1p63

\begin{abstract}
With the quick emergence of computers and related technology, Electronic-learning (E-learning) and Information Communication and Technology (ICT) have been extensively utilized in the education and training field. Miscellaneous methods of integrating computer technology and the context in which computers are used have affected student learning in many different ways. Integration of technology can help to create courses that are easier and more effective for learners, especially if ICT and E-learning are integrated into the educational process. ICT, when used in a sufficient and suitable manner, can help learners to understand IT better. Moreover, it can help learners to use the absolutely necessary skills which can guarantee success in empowering the learners with IT awareness and skills which are essential for success in today's knowledge economy. This study aims to conduct a survey on the role of E-learning and ICT courses in educational environment. By having ICT courses available online via E-learning, every learner will adapt and be comfortable with the continuous upcoming technologies and innovations.
\end{abstract}

Keywords: information and communication technology (ICT), online-learning, electronic-learning (e-learning), ICT course

\section{Introduction}

Computers have become an absolutely necessary gadget for living. The main reason is that they function as a gateway into the World Wide Web. Because of the continuous developments of computer technology and Internet available to most teachers, educational technology has become increasingly more important. Every learning Educational Institution needs a structure that provides its Academic Staff with the essential means to encourage better institutional involvement. Within these higher educations, virtual learning environments (VLE), learning management systems (LMS), web-based trainings (WBT) and other Electronic-learning (E-learning) applications and educational technologies should be easily within reach of different kinds of people (Debevc et al., 2007). Today, schools are continuously disputed by the increased visibility, roles and cost of educational technology. Many research studies have suggested that the integration of technology can improve academic performance, enhance motivation, and promote learning (Curtin, 2002).

\section{E-Learning and ICT Courses in Education}

Learning concerns skills that could be measured and transferred from one person to another. The skills can develop performance in different fields of study (Dewey, 1966). E-learning is also known as learning by electronic means in advanced online-learning in virtual learning environments. The development of a successful E-learning in educational institutions and large societies is possible. By uploading the documents online, individuals can download and learn them offline. Perhaps at the present time online-learning environments are the most widespread and the most expensive equipment in educational technology (Salinas, 2008; West et al., 2007).

The developments of Information Technology (IT) and the communication, organization and pedagogy inspire E-learning. Many different fields which are filled with these IT innovations are intended for education and training purposes, research and development purposes, consultation and project work. Moreover, the planning and support for an educational institution to enhance its ability and standardize its capability is by identifying necessary improvements in its current performance. Nevertheless, the online environment must permit for 
different technical platforms, organizational models and pedagogical beliefs.

\subsection{Education via E-Learning}

E-learning is convenient as it can be done anywhere, at any time. The E-learning advancement approaches has become more improvised with the continuous developments of technologies; thus Academic Staffs should always be efficiently consistent and steadily up-to-date, incorporating these rapid developments into the web-based environment. Palloff and Pratt (2003) claimed that new delivery media and technology breakthroughs could affect teaching and learning environment; nevertheless the aims will not change, which is to satisfy the needs of the learners (Palloff \& Pratt, 2003). Preparing courses for these learners by the Academic Staffs should be versatile whether it is through the existing face-to-face environment or online-learning environment.

However, subject to learning in an online-virtual environment, Bolliger and Wasilik (2009) stated that although Academic staffs play a primary role in the use of online-learning environment by students, these students can only utilize those that the academic staff make available to them, in a specific learning context (Bolliger \& Wasilik, 2009). Online teaching does allow teachers and students to work from all around the globe, with Internet connectivity, however it significantly increases the teachers' effort per student.

Although online teaching does allow teachers and students to work from all around the globe with Internet connectivity, it significantly increases the teachers' effort per student. There are researchers that do not agree with the impact of technology on E-learning. To name a few, Theofanos and Redish (2003) argued that it is not enough to have guidelines that are based on technology. They believe that it is necessary to understand the users, and how they work with the tools, in order to truly meet the need of users (Theofanos \& Redish, 2003). Similarly, Carlson and Everett (2000) disagree with this and claim that taking an existing face-to-face course and only publishing course materials into a Web-based environment will not necessarily present the basis for a course which is carefully planned; this is because the course must be adapted to the environment to take advantage of the technology available (Carlson \& Everett, 2000). Treviranus (1999) also alleged that there are disadvantages to computer-mediated medium, for example it reduced face-to-face human contact with greater dependence on technology. With regards to disable individual, He also claimed that study choices are also limited to only available multimedia offerings (Treviranus, 1999).

\subsubsection{E-Learning Organization in Educational Institution}

Now to have an Educational Institution that is strongly capable of handling E-learning systems embedded in their organization is definitely not easy. Laurillard (1997) claimed that to improve the organizational E-learning capability, they must identify the limitations with current institutional E-learning practices, which results in high quality software development (Laurillard, 1997). To achieve a greater E-learning development level, this does reflect the institutions; because institutions must have a continuous on-going involvement in the process, which may disrupt self-satisfaction. After all, Educational Institutions objectives are common, which is to maintain an effective high level of E-learning process capability in today's rapidly changing Information Communication and Technology (ICT) environment. In addition, Berge et al. (2000) argued that the conventional styles of education can be challenged in this new environment. The environment could also put forward new teaching and learning standards which are suitable for modern technology (Berge et al., 2000).

E-learning is the convergence of the web and learning on all levels, whether it is elementary school, college, or business. E-learning creates new challenges for teaching staff, curriculum support services, disability support services and institutional administrators. Teaching staff needs to accommodate diversity within their curriculum, for example the way they design their subjects, plan the learning experiences, identify the learning materials and assess the outcomes. Moreover, teaching staff needs to develop expertise and IT skills in creating learning experiences that utilize the E-learning technology, like designing curriculum materials that can be placed on the Internet or stored on CD ROM. The present advancement in IT electronic media communication like World Wide Web is used so that people can give lectures online.

\subsection{ICT in Education}

Many research studies have suggested that the integration of ICT can improve academic performance, enhance motivation, and promote learning. ICT can effectively facilitate the feasibility of E-learning. Curtin (2002) gave a definition of ICT as a series of activities which make the capturing, storing, processing, transferring, and presenting of information easier (Curtin, 2002). According to Baron and Greenberg (1986), while information as the organization support is knowledge, intelligence or education; IT is the e-technology concerning collecting, storing, and transferring information; which is thought of in terms of media or skills of a communication organization (Baron \& Greenberg 1986). Media are forms of communications by means of which teaching and 
learning can happen, quoted Ogunmilade (1984). Communication is basically a sharing process of a bilateral exchange between two or more people, existing anywhere (Cole, 1990). It is a process of creating, transferring, and understanding ideas, facts such as mental ideas and emotions; therefore it is 'the process of transferring and interpretation of information among individuals, (Hoy \& Miskel, 1990). The United Nations Scientific, Educational and Cultural Organization (UNESCO) defined ICT as the action of putting the computer, telecommunication, and media technologies together (UNESCO, 2005).

According to Oh and French (2004), in a paper on Introductory Instructional Technology Course, it is claimed that recent studies on this technology integration into education suggest that pre-service teachers should correctly use computer technology for teaching and learning (Oh \& French, 2004). They found that the students enrolled in this course believed they were adequately prepared to implement technology in their teaching and learning practice, as they felt they had the basic skills and concepts to operate computers, and could apply technology enhanced curriculum to support higher students' thinking skills and creativity. Higher Educational research and practice demonstrate that different ways of integrating computer technology and the context in which computers are used have changed the effects on student learning.

In Keegan's (2008) research on 'The impact of new technologies on distance learning students', the study approved that people usually agree that using technology in higher levels of education is detrimental for all students in general (Keegan, 2008). Most of the attendance in the study confirmed that using ITC can support learning and teaching. It will also make it easier for students to have access to student administrative processes, so that distant education can be facilitated. Most participants claimed that they were particularly enthusiastic about using ICT so that they could give and take information and' communicate with the tutor' and 'share information and ideas with people from the team'. Other researchers (Chou \& Liu, 2005; Schulz-Zander et al., 2002) have indeed shown that with the help of a web-based virtual learning environment, distance learning is both effective and useful. Touching on the distance education study, other researchers (Anja \& Ngwo, 2007) stated that knowledge, tools and methods, which designate technology, are absolutely essential in every present organization. Technology has brought many functions in educational institutions like schools, colleges and universities for the teaching and learning processes whether to public or private sectors. Moreover, ICT course content integrated into the Web could be an alternative for the Educational Institutions to deliver their courseware lectures, should lectures are be canceled in a given scenario. Hence, these institutions should make every effort to fully-utilize ICT.

Taking an example of students in Nigeria by Yusuf and Yusuf (2009), the education systems for students in Nigeria include three categories which are the primary school,( introducing essential computer skills, using the computer to make learning easier, having basic skills for writing texts, computing, and putting information into computer); the high schools(to organize curriculum on computer learning and teaching, to consider unity schools as the pilot schools for computer teaching and learning);and to choose tertiary schools to present computer science as a compulsory course for the students, and also include computer science as indispensible in the management of school and teaching; and other elements like equipment requirement, the training of teachers , and special suggestions on various tertiary schools) (Yusuf \& Yusuf, 2009).

\subsubsection{ICT Courses via E-Learning}

Today, E-learning is a rich and complex concept, as it is the provision of education and training via the World Wide Web for students. Within these higher educations, virtual learning environments (VLE), learning management systems (LMS), web-based trainings (WBT) and other E-learning applications and educational technologies are accessible to all type of individuals. Making E-learning and educational technology accessible means that all these three parts (content, communication, construction) of the three-component-model must be taken in consideration and made accessible (Fisseler \& Bühler, 2007). By adapting into this learning management system, it facilitates content creation and content adaptation and the learners get a wide range of standardized user interaction possibilities. Moreover, in these virtual learning environments, it is important to ensure scalability of the platform, support for portability and standards as well as content personalization. Kante (2003) quoted that ICT, when used in a sufficient and suitable manner, can help learners to understand IT better. Moreover, it can help learners to use the absolutely necessary skills which can guarantee success in empower the learners with IT awareness and skills which are essential for success in today's knowledge economy (Kante, 2003).

ICT is the process of putting together the potentials of computer, telecommunication, and electronic media by means of electronic technology. Digital technology generates greater access and equity to information for the Hearing-Impaired Individuals; for example, the Broadband video-telephony now that enables the 
Hearing-Impaired Individuals to communicate via the telephone line using sign language (McCaul, 1997). ICT has had positive impacts on different aspects of man's life. Therefore, it has brought about a strong stimulus to change people's way of life, to transfer and process information.

\section{Computer Science in Education}

The field of computer science offers challenging, high-paying careers which are more accessible than other careers. Computer Science Education has increasingly become a popular major, not only for the normal individuals, but for the disabled individuals too. Accessibility education has become an emerging topic in Computer Science Education. Web accessibility defines the ability for everyone in society to have the right to use any software, hardware or any assistive technologies to understand and fully interact with the website content, regardless disability, geographical location, language barriers, or other impairing factor (Sierkowski, 2002; Thatcher et al., 2002).

Relating to the Computer Science Education; Orhun (2009) developed a project portal that brings together all academic requirements and practical information from the partner universities necessary for student mobility (Orhun, 2009). This portal intended to integrate multidisciplinary knowledge into current core computer science courses to teach to undergraduate and master students. Other Courses include the ambient computing curriculum which has aspects of social science, cognitive science, human-computer interaction, organizational studies, global studies, and particular application areas. In another research entitled 'Learning Software Engineering via Internet' (Weber-Wulff \& Schmiedecke, 2005) discussed a successful report on E-learning module on Software Engineering, which is used at the VFH (Virtual University of Applied Sciences). Here, their goal which was to be able to automatically design a personalized E-learning course that can meet the learner's knowledge and needs - was reported as a successful one.

In another research touching on Computer Science, a paper on Introductory Computer Science course by Ahmed Akour (2008) studied The Effects of Computer-Assisted Instruction (CAI), and argued that Learners uses CAI as an instruction medium, as CAI is one of the most rapidly advancing and interesting medium of instruction in recent years (Ahmed Akour, 2008). Hoska (1993) stated that CAI is one of the most common forms of integrating computers into the instructional process; since it's a learning environment that supports a one-on-one interaction between learners and a computer program (Hoska, 1993). ICT-based learning is an active way of presenting teaching equipment to deliver education. Back to the Introductory course, which provides an introduction to the ICT notions, computer hardware and software, networks, and internet, show that through the recent years of development, computers and communications technology have sharply changed the delivery medium of education. With the extraordinary computer storage, computer delivery capabilities, breakthroughs in software and modern communications technologies, it is likely that education can be presented in new meaningful ways (Ahmed Akour, 2008).

Moreover, with online-learning, in advancing student knowledge and skills of self-learning, CAI is frequently used to entertain them (for a case of computer games); argued (Schwier \& Misanchuk, 1993). This research was further studied by Lunts (2002) claiming that CAI learning environment does support direct interaction between a learner and a computer program (Lunts, 2002). This CAI means of instruction can manage the flow of educational instructional materials, seeing, hearing, reading, and actively producing materials at their own pace.

\section{ICT in Education via Online-Learning Environment}

ICT Education is important for individuals to be consistent in the Computer Education era. With the much information all over the web, and the various ways to communicate with each other through the web, it eases these individuals to interact with one another via online; supported by the latest technology. Determining the Web interaction provides the types and strength of communication framework for the ICT courses, meaning the synchronous and asynchronous communication equipment used, like e-mail, electronic bulletin boards, and chat rooms. According to Trucano, ICT has the potential for not only presenting new teaching and learning performance, but also for acting as a trigger for revolutionizing the education system. It can help teachers and learners and promote the development of vital skills for the 21 st century workplace (Trucano, 2005). Trucano (2005) and Carnoy (2004) alleged that researchers have been inconclusive on the expectations concerning the worth of ICT (Carnoy, 2004); although ICT has the ability to improve the tools and learning environment since it lets materials be offered in multiple media, motivates and involves students in the learning activity, develops questioning and exploration, and provides access to worldwide sources of information all over the world within reach, to name but a few. 


\subsection{ICT in Higher Education Augments Online-Learning}

Many areas of research studies have been integrating E-learning into practice. This is because an E-learning model does give a sense of direction for higher Educational Institutions to improve their E-learning processes in a long term institutional planning (Bolliger \& Wasilik, 2009). Making online-learning contents accessible to all e-learners has become the most important aspect for most E-learning content providers. The design of E-learning content is not a simple process; as the content should be carefully planned, designed and evaluated in order to ensure efficient and simple use. In fact, accessible E-learning allows distance and flexible educational activities; therefore individuals are not missing any particular access capabilities, and do not miss the social inclusion of non-typical learners (Savidis \& Stephanidis, 2005; Seale, 2004). Today, E-learning has changed from the physical face-to-face education to a virtual environment. However, still Educational Institutions have a common approach for teaching their many students in a lecture-based course. As universities look into other alternatives to accommodate these high number of students and their learning needs, E-learning is suggested to provide an attractive delivery mode for teaching large, on-campus courses (Savidis \& Stephanidis, 2005). A research by Nordin and Zakaria (2007) investigated the use of E-learning among future school heads in education management and leadership, which involved two phases that is the design and development of an E-learning system using Moodle, and the second phase was the evaluation in terms of E-learning content, knowledge, usage, skills and cognitive level. In this research, the results were successful in promoting teaching and learning strategies to a higher degree.

Although technologies are growing rapidly, many higher Educational Institutions automatically adopted this online-learning environment steadily, as discussed (Reynolds et al., 2003), without even evaluating its effectiveness (Mahdizadeh et al., 2008). This virtual environment requires institutions to accept a serious approach to E-learning improvements, which benefits an institution as a whole. Achieving a higher E-learning development level in this environment does reflect the institutions; by monitoring how well it is delivering E-learning across the globe. After all, the overall goal of virtual environment is to maintain a high level of E-learning process capability in today's rapidly changing ICT era.

Likewise, Boettcher and Conrad (2004) stated that using of electronic technologies in education will steadily grow, and universities will always look for ways to use on-line tools to deliver instruction as the technological infrastructure expands in terms of its capabilities and power. According to them, E-learning is really useful for working together, communicating, and dispersal of information. ICTs really perform a valuable function in the development of a knowledge-based society since they increase the production, delivery, and use of knowledge. Higher Education's roles and processes have sharply changed because of the growing effects of ICTs. Christie et al. (2002) argued that ICTs drastically changing both workplaces and the educational site (Christie et al., 2002). This was previously debated by Breen et al. (2001) and Wenglinski (1998) who also alleged that the growth in the educational use of ICTs does prove that these modern technologies can facilitate education (Breen et al., 2001; Wenglinski, 1998).

\subsection{Impact of ICT and Digital Technologies on Online-Education}

In Education, Maisamari (2003) alleged that with multiple advances in telecommunications technology has enabled students to be anywhere and yet still receiving tutorials, lectures and instructions from their teachers without having to have any physical contacts (Maisamari, 2003). Although there is no personal contact, electronic technologies are only used for transferring information, and curriculum can still be carried out. According to Dirckinck-Holmfeld and Lorentsen (2003), using ICT to develop and present curricular in education are the most productive use (Dirckinck-Holmfeld \& Lorentsen, 2003). Therefore, since teaching and practice often reflects in the social and economic development, ICTs integration in education has resulted in significant breakthroughs in teaching and learning (Senyapili \& Karakaya, 2005).

Embedded in this web-based E-learning platform, each and every E-learners will be exploited with the various latest technologies and devices developed to match their skill-requirements. Many research studies have suggested that the integration of technology can improve academic performance, enhance motivation, and promote learning. Salomoni et al. (2008) presented a practical approach that enables to fully profile these E-learners; by considering the user's physical human needs and the technical characteristics of the device they use. This profiling method developed, were able to dynamically adapt online-learning materials (Salomoni et al., 2008).

\section{Summary}

Educational research and practice, demonstrate that different ways of integrating computer technology and the context in which computers are used have varied effects on student learning. A situational analysis of the issue of 
computer education in the school clarified the need for staff development and a process for educational change in the area of computer-based instruction. With the extraordinary computer storage, computer delivery capabilities, and breakthroughs in modern software and communications technologies, E-learning is likely to involve different senses, record and evaluate learner's alternatives and performance, and propose remedial feedback according to the learner's performance. Growth of ICT and E-learning courses in education has resulted in chances to improve the different levels of the process of information, mainly in universities. ICT and E-learning which act as the combination of the potentials of computer, telecommunication, and electronic media using the digital technology; has positively affected different areas of human existence, thereby creating a powerful drive for changes in the way human beings live, transfer information, process information, and carry on businesses. By using these new tools effectively, every Individual will adapt and be comfortable with the continuous upcoming technologies and innovations.

\section{References}

Ahmed Akour, M. A. (2008). The Effects of Computer-Assisted Instruction on Jordanian College Students' Achievements in an Introductory Computer Science Course. Electronic Journal for the Integration of Technology in Education, 5, 16-23.

Anja, S. N. (2007). Information and communication technology as synergy for sourcing distance education: The feasibility in Cameroon education system. Department of Science of Education - ENSAB, University of Yaounde I, Republic of Cameroun.

Baron, R. A., \& Greenberg, J. (1986). Behaviour in organisations. Understanding and managing the human side of work. London: Allyn and Bacon Inc. Chambers English Dictionary (1990).

Berge, Z. L., Collins, M., \& Dougherty, K. (2000). Design guidelines for Web-based courses. In B. Abbey (Ed.), Instructional and cognitive impacts of Web-based education (pp. 32-40). Hershey, PA: Idea Group; 2000.

Boettcher, J., \& Conrad, R. M. (2004). Faculty Guide for Moving Teaching and Learning to the Web. League for Innovation in the Community College, Laguna Hills, CA.

Bolliger, D. U., \& Wasilik, O. (2009). Factors influencing faculty satisfaction with online teaching and learning in higher education. Distance Education, 30(1), 103-116.

Breen, R., Lindsay, R., Jenkins, A., \& Smith, P. (2001). The role of information and communication technologies in a university learning environment. Studies in Higher Education, 26, 95-114.

Carlson, R., \& Everett, D. (2000). Taking instruction online. In Electronic Proceedings of the Mid-South Instructional Technology Conference: Extending the frontiers of teaching and learning.

Carnoy, M. (2004). ICT in education: Possibilities and challenges. Inaugural Lecture of the Universitat Oberta de Catalunya (UOC) 2004-2005 Academic Year

Chou, S. W., \& Liu, C. (2005). Learning effectiveness in a Web-based virtual learning environment: A learner control perspective. Journal of Computer Assisted Learning, 21(1).

Christie, M., Jaun, A., \& Jonsson, L. (2002). Evaluating the use of ICT in engineering education. Eur. J. Eng. Educ., 27(1), 13-20.

Cole, G. A. (1990). Management theory and practice. London: D. P. Publications Ltd.

Curtin, R. (2002). Promoting youth employment through information and communication technology (ICT): Best practice example in Asia and the Pacific.

Debevc, M., Petra, P., Mateja, V., \& Zoran, S. (2007). Exploring Usability and Accessibility of an E-Learning System for Improving Computer Literacy. In Proceedings of ICTA.

Dewey, J. (1966). Democracy and Education. Toronto: Collier-Macmillan Canada.

Dirckinck-Holmfeld, L., \& Lorentsen, A. (2003). Transforming university practice through ICT-Integrated perspectives on organizational, technological, and pedagogical change. Interactive Learning Environments, 11(2), 91-110.

Fisseler, B., \& Bühler, C. (2007). Accessible E-Learning and Educational Technology Extending Learning Opportunities for People with Disabilities. Proceedings of the International Conference of "Interactive computer aided learning" ICL2007: E-Portfolio and Quality in e-Learning.

Hoska, D. M. (1993). Motivating learners through CBI feedback: Developing a positive learner perspective. In V. Dempsey, \& G. C. Sales (Eds.), Interactive instruction and feedback (pp. 105-132). Englewood Cliffs, N.J.: 
Educational Technology Publications.

Hoy, W. K., \& Miskel, C. G. (1990). Educational administration: Theory research and practice. New York: Random House. Inc. Jomtien Conference, (March, 1990). Education for all EFA-Thailand, 1978.

Kante, C. (2003). E-Learning: The new frontier in the developing world. TechKnowLogia, 15-19.

Keegan, D. (2008). The impact of new technologies on distance learning students. E-learning \& Education, 4.

Laurillard, D. (1997). Rethinking University Teaching: A Framework for the Effective Use of Educational Technology. London: Rutledge.

Lunts, E. (2002). What does the literature say about the effectiveness of learner control in computer-assisted instruction? Electronic Journal for the Integration of Technology in Education, 1(2), 59-75. Retrieved from http://ejite.isu.edu/Volume1No2/Lunts.pdf (accessed 3/4/2009)

Mahdizadeh, H., Biemans, H., \& Mulder, M. (2008). Determining factors of the use of e-learning environments by university teachers. Computers \& Education, 51(1), 142-154.

Maisamari, A. M. (2003). Resource management through distance education. J. WCCI Nigerian Chapter, 4(2), $242-250$

McCaul, T. F. (1997). Video-based telecommunications technology and the Deaf community (Research Summary). Brisbane: Australian Communication Exchange Ltd.

Nordin, N., \& Zakaria, E. (2007). Using Computer in Learning Mathematics. In E. Zakaria, N. M. Nordin, \& S. Ahmad (Eds.), Trend in Teaching and Learning Mathematics (pp. 1-14). Kuala Lumpur: Utusan Publications.

Ogunmilade, C. A. (1984). Media in Education. Ile-Ife University of life Press Ltd.

Oh, E., \& French, Dr. (2004). Pre-service Teachers' Perceptions of an Introductory Instructional Technology Course. Electronic Journal for the Integration of Technology in Education, 3, 1.

Orhun, E. (2009). International Cooperation in Ambient Computing Education. Proceedings of the Fourth Colloquium on International Engineering Education, May 20, 2009, San Diego State University, California.

Pallof, R., \& Pratt, K. (2003). The virtual student: A profile guide to working with online learners. San Francisco: Jossey-Bass.

Reynolds, D., Treharne, D., \& Tripp, H. (2003). ICT - the hopes and the reality. British Journal of Educational Technology, 34(2), 151-167.

Salinas, M. F. (2008). From Dewey to Gates: A model to integrate psychoeducational principles in the selection and use of instructional technology. Computers \& Education, 50(3), 652-660.

Salomoni, P., Mirri, S., Ferretti, S., \& Roccetti, M. (2008). Education. Human-Computer Interaction Series, 263-271. Springer London. http://dx.doi.org/10.1007/978-1-84800-050-6_15

Savidis, A., \& Stephanidis, C. (2005). Developing inclusive elearning and e-entertainment to effectively accommodate learning difficulties. ACM SIGACCESS Accessibility and Computing, 83, 42-54.

Schulz-Zander, R., Büchter, A., \& Dalmer, R. (2002). The role of ICT as a promoter of students' cooperation. Journal of Computer Assisted Learning, 18(4), 438.

Schwier, R. A., \& Misanchuk, E. R. (1993). Interactive multimedia instruction. Englewood Cliffs, NJ: Educational Technology Publications.

Seale, J. (2004). The development of accessibility practices in e-learning: An exploration of communities of practice. ALT-J Research in Learning Technology, 12(1), 51-63.

Senyapilı, B., \& Karakaya, A. (2005). Design studio communication: Young generation holding on to old techniques. Innovation in Architecture, Engineering and Construction, 375-385. Rotterdam: Optima Grafische Communicatie.

Sierkowski, B. (2002). Achieving Web Accessibility. SIGUCCS 02: Proceedings of 30th ACM SIGUCCS conference on User services (pp. 288-291). ACM Press.

Thatcher, J., Bohman, P., Burks, M., Henry, S. L., Regan, B., Swierenga, S., \& Urban, M. (2002). Constructing Accessible Web Sites. Glasshaus.

Theofanos, M. F., \& Redish, J. (2003). Bridging the gap: Between accessibility and usability. Interactions, 6(10), $36-51$. 
Treviranus, J. (1999). Adding feeling, sound and equal access to distance education.

Trucano, M. (2005). Knowledge maps: ICTs in education [On-line]. Washington DC: InfoDev/World Bank.

United Nations Scientific, Educational and Cultural Organization (UNESCO). (2005a). Information and communication technologies in schools, A handbook for teachers. Paris: Author.

Weber-Wulff, D., \& Schmiedecke, I. (2005). Learning Software Engineering via Internet. eleed, Iss.

Wenglinski, H. (1998). Does it compute? The relationship between educational technology and student achievement in mathematics. Princeton, NJ: ETS.

West, R., Waddoups, G., \& Graham, C. (2007). Understanding the experiences of instructors as they adopt a course management system. Educational Technology Research and Development, 55(1), 1-26.

Yusuf, M. O., \& Yusuf, H. T. (2009). Educational reforms in Nigeria. The potentials of information and communication technology (ICT), 4(5), 225-230.

\section{Copyrights}

Copyright for this article is retained by the author(s), with first publication rights granted to the journal.

This is an open-access article distributed under the terms and conditions of the Creative Commons Attribution license (http://creativecommons.org/licenses/by/3.0/). 